\title{
UN JARDÍN PARA LA INFANCIA. METÁFORA COMENIANA RECREADA EN NUESTROS TIEMPOS ${ }^{\star}$
}

\author{
A Garden for Childhood. \\ A Comeniana metaphor recreated in our times
}

\author{
María Esther Aguirre Lora ${ }^{\beta}$ \\ Fecha de recepción: 19/09/2018 • Fecha de aceptación: 17/10/2018
}

Se me ocurre que hemos caminado más

de lo que llevamos andando.

Juan Rulfo

Resumen. El Jardín de Niños como tal, bajo el nombre Kindergarten, se introdujo en México como una de las novedades de la modernidad porfiriana, a través de las cuales se querían revertir las prácticas que existían en relación con la conducción de infantes. La visita de dos maestras mexicanas con el móvil de documentar la existencia de las opciones que se practicaban en Estados Unidos con muy buenos resultados las puso en contacto con programas, materiales y experiencias que procedían de Friedrich Fröbel (1782-1864) y habían sido ampliamente difundidas en países europeos. El propósito de este texto es marcar los orígenes de esta institución, el Jardín de Niños, más allá del siglo XIX en una metáfora del pensador moravo Juan Amós Comenio (1572-1670) en el contexto de las reformas religiosas. Estructuro el artículo en tres ejes: 1) Notas sobre las aportaciones de la metáfora como herramienta analítica; 2) En torno al establecimiento del Jardín de Niños como institución; 3) Juan Amos Comenio y la metáfora del jardín de niños.

Palabras clave: Jardín de Niños; México; Metáforas; Juan Amós Comenio; Fröbel.

\footnotetext{
\& Agradezco a la Dra. Dana Večeřová, del Museo Comeniano Juan Amós Comenio de Uherský Brod, sus valiosas gestiones para la obtención y uso de las imágenes que introduzco en este texto, procedentes de la Biblioteca Nacional de Praga.

${ }^{\text {B }}$ Instituto de Investigaciones sobre la Universidad, Universidad Nacional Autónoma de México. Lado norte de la Sala de Conciertos Nezahualcóyotl. Centro Cultural Universitario. Delegación Coyoacán. 04510 Ciudad de México. mariaestheraguirre@gmail.com / lora@unam.mx
}

Cómo citar este artículo: Aguirre Lora, María Esther. «Un jardín para la infancia. Metáfora comeniana recreada en nuestros tiempos». Historia y Memoria de la Educación 9 (2019): 319-341. 
Abstract. The Children's Garden as such, under the name Kindergarten, was introduced in Mexico as one of the novelties of the Porfirian modernity, and was meant to revert to practices that existed in relation to the instruction of infants. The visit of two Mexican teachers whose purpose was to document the existence of options practiced very successfully in the United States put them in contact with programs, materials and experiences designed by Friedrich Fröbel (1782-1864) that had been widely disseminated in European countries. The purpose of this text is to trace the origins of this institution, the Children's Garden, beyond the nineteenth century, in a metaphor of the Moravian thinker Juan Amós Comenio (1572-1670) in the context of religious reforms. I have structured the article on three axes: 1) Notes on the contributions of the metaphor as an analytical tool; 2) Regarding the establishment of the Kindergarten as an institution; 3) Juan Amos Comenio and the metaphor of the children's garden.

Keywords: Kindergarten; Mexico; Metaphors; Juan Amós Comenio; Fröbel.

\section{NOTAS SOBRE LA METÁFORA}

Las metáforas ${ }^{1}$ están presentes en nuestro lenguaje cotidiano pasando, la mayoría de las veces, inadvertidas: atraviesan comportamientos, formas de hacer y de pensar; nombran procesos, instituciones y papeles de sus protagonistas; permean la producción de distintos campos del conocimiento. Forman parte de los recursos lingüísticos poniendo de manifiesto el lugar desde el cual se emite el discurso, cuyo significado, a menudo, requiere desentrañarse. Sin embargo, a pesar de la naturalidad con que recurrimos a las metáforas, éstas no son banales, ni constituyen un simple adorno del lenguaje. Tampoco se limitan, como el símil, a establecer de manera evidente el término de la comparación; requieren de una constante interpretación que pone en juego la dimensión dialogal, la posibilidad de comunicación y la interpretación del escucha. Es así que el significado de la metáfora

\footnotetext{
1 «Una metáfora es una figura retórica o tropo en el que se traslada el significado de un concepto a otro, estableciendo una relación de semejanza o analogía entre ambos términos. Las metáforas son imágenes, conceptos o ideas que guardan entre sí una relación sutil que es convocada o sugerida cuando aparecen asociadas en un texto, y que produce relaciones impresionantes que redimensionan el significado literal de las palabras. La palabra, como tal, procede del latín metaphŏra, que deriva del griego $\mu \varepsilon \tau \alpha \varphi \rho \rho \alpha ́$ (metaphorá) que significa "traslación", "desplazamiento"» (s.v. Metáfora, en Significados.com. Disponible en: https://www.significados.com/metafora/ Consultado: 23 de julio de 2018).
} 
no ha de buscarse literalmente, sino rastrearse en el plano de lo simbólico y lo conceptual.

Estamos de acuerdo con Amilburu, para quien:

La creación y el uso de metáforas proyecta una luz nueva que permite ver desde una perspectiva diferente algún aspecto de la realidad, una región del saber que hasta entonces había sido impenetrable para la comprensión o permanecía oscurecida, quizá por la sobreabundancia de lenguaje especializado. Así pues, las metáforas introducen nuevos puntos de vista, iluminan el pensamiento a través de las oportunas comparaciones o contrastes, ponen énfasis en algunas cuestiones, ilustran algunos aspectos de la argumentación, etc. ${ }^{2}$

No obstante, la presencia de las metáforas en el curso del tiempo, es a horcajadas de la década de los sesenta y setenta cuando comenzaron a estudiarse como un recurso vinculado a la producción de conocimiento, como una herramienta para el análisis de las formas de pensar y de razonar sobre determinados problemas, como una vía para teorizar sobre nuestra percepción de la realidad.

Sin lugar a dudas un hito destacado en relación con la importancia que la metáfora adquirió en el campo de la lingüística, de su proyección a otros campos disciplinares y de su estudio por profesionales de diversas procedencias, fue la publicación de Paul Ricoeur, La métaphore vive (Paris, Seuil,1975), cuyo título, ya en sí mismo resultaba sugerente en la medida en que irrumpía en la condición aparentemente estática del recurso. La obra abría el horizonte de interpretación al señalar, entre otras, dos funciones, la retórica, vinculada al embellecimiento del discurso y sus posibilidades de persuasión, y la poética, que daba cuenta de las posibilidades de la inventiva para proponer nuevos discursos.

En el caso del campo educativo las iniciativas para valerse de esta herramienta de análisis, procedentes de filósofos, epistemólogos, científicos sociales, educadores, no se hicieron esperar, como fue el caso de Israel Scheffler (1960), Elliot W. Eisner (1969), Hugh G. Petrie (1976),

\footnotetext{
${ }^{2}$ María G. Amilburu. «Las metáforas de la educación». En Antropología de la Educación, eds. Henri Bouché y otros (Madrid: Síntesis, 2002): 187-206 (cita en 189).
} 
Andrew Ortony (1978), entre otros, que se dieron a la tarea de analizar el papel de las metáforas en la educación, ${ }^{3}$ estudios que se irían incrementado hasta llegar a nuestros días para repensar los procesos, instituciones, prácticas, protagonistas (escolarización como engranaje, escuela como cárcel, alumno como esponja o tabula rasa, maestro como artesano) desde nuevos ángulos. ${ }^{4}$ De hecho, este nuevo horizonte de interpretación nos plantea un deslizamiento paradigmático que recurre a vías metodológicas vinculadas con la investigación de corte interpretativo, con la fenomenología y con la hermenéutica. Por su parte, las teorías constructivistas han jugado una parte importante en ello, en tanto que han hecho hincapié en la construcción social de imaginarios con respecto a la educación, en la construcción de narrativas personales que dan sentido al mundo. ${ }^{5}$

Las metáforas se pueden acotar desde varios puntos de vista, pero, necesariamente, expresan el pulso de los tiempos en que se producen, el lenguaje, las preocupaciones y las circunstancias de la época.

Fue precisamente E.W. Eisner, desde la perspectiva de la educación en artes visuales y las metáforas visuales, quien ya en 1969 señalaba el uso de tres metáforas básicas en educación: la industrial, como proceso de producción cercano a las maquinarias; la de comportamiento, que enfatiza el aspecto de conducción; y la biológica, vinculada con los procesos de crecimiento propios de las plantas de manera semejante a como ocurre en la naturaleza, cuyo cuidado y disposición remite a las labores propias de la jardinería. Es en este último grupo de metáforas en el que se inscribió el Jardín de Niños,

\footnotetext{
${ }^{3}$ Israel Scheffler, The Language of Education (Illinois: Thomas, Springfield, 1960); Elliot W. Eisner, «Instructional and Expresive Objectives: Their Formulation and Use in Curriculum», AERA Monograph Series in Curriculum Evaluation 3 (1969, reimpreso en 1985): 1-21; Hugh G. Petrie, «Do you see what I see? The epistemology of interdisciplinary inquiry», Educational Researcher 5, no. 2 (1976): 9-15; Andrew Ortonys, «Metaphor: Theoretical and empirical research», Psychological Bulletin 85, no. 5 (1978): 919-943.

${ }^{4}$ Pueden citarse, entre otros, los estudios de José Luis Rodríguez Diéguez, «Las metáforas en la enseñanza». Enseñanza \& Teaching, Revista interuniversitaria de didáctica 6 (1988): 205-222; Ángeles Molina Iturrondo, «Las educadoras y sus metáforas educativas: dos investigaciones en acción», Anales de Pedagogía 19 (2001): 201-220; Rosa Vázquez Recio, «Las metáforas, una vía posible para comprender y explicar las organizaciones escolares y la dirección de centros», REICE-Revista Electrónica Iberoamericana sobre Calidad, Eficacia y Cambio en Educación 5, no. 3 (2007): 137-151; Amilburu, «Las metáforas de la educación».

5 Jerome Bruner, La educación, puerta de la cultura (Madrid: Visor, 1997).
} 
con la propuesta de una institución innovadora para la conducción de los niños pequeños.

\section{TIEMPOS DE REVOLUCIONES Y UTOPÍAS: EN TORNO AL ESTABLECIMIENTO DEL KINDERGARTEN [JARDÍN DE NIÑOS]}

Desde mediados del siglo XvIII la modernidad, con sus vientos renovadores, se multiplicarían en Occidente las revoluciones industriales, emblemáticas del movimiento económico y las nuevas formas de organización social y del trabajo que impactarían profundamente el plano de la vida cotidiana, de las expectativas, del modo en que personas y grupos sociales se percibirían a sí mismas, de las fracturas entre el campo y la ciudad, de la composición social. Por otra parte, la Ilustración, como movimiento intelectual, político y cultural impulsado por las élites (algunos aristócratas, algunos burgueses en ascenso, algunos clérigos), marcaría el rumbo de los programas y de las políticas que se pondrían en marcha. ${ }^{6}$

El panorama que se presentó era sumamente complejo y movedizo; abría fracturas y campos de tensión nuevos en relación con situaciones que ya se venían gestando desde años anteriores. La primera revolución industrial (Gran Bretaña, 1760-1860), con una producción a gran escala, redundaría en importantes e insospechados intercambios económicos, de composición social y culturales en medio de los cuales se manifestaba el muy alto costo del progreso. La situación llegó a ser tan grave que llevó a los pensadores y políticos a tratar de explicarse, desde distintos ángulos, lo que se llamaría la 'cuestión social'. ${ }^{7}$ Relevante, para los propósitos de este texto, es que la situación se volvió tan problemá-

\footnotetext{
${ }^{6}$ Se trata de un movimiento que, partiendo de Inglaterra con la discusión sobre las nuevas formas de producción industrial, se introduce en Francia por Voltaire (1694-1778) y da lugar al grupo de enciclopedistas tales como Diderot (1713-1784), Montesquieu (1689-1755), D'Alembert (17171783), Rousseau (1712-1778), entre otros. En España, y a través de ella, a sus virreinatos, lo ponen en marcha los Borbones (Fernando VI, Carlos III); Alemania, por su parte, aporta el Iluminismo, inicialmente a través de Kant (1724-1804).

${ }^{7}$ En el núcleo de teorías políticas y sociales que comenzaron a gestarse en los países anglosajones, al margen de la Iglesia Católica y en el terreno de las Iglesias reformadas, surgieron pensadores inscritos en los primeros trazos del liberalismo, tales como Adam Smith (1723-1790), Jeremy Bentham (1748-1832), David Ricardo (1772-1823) y Thomas Robert Malthus (17761834).
} 
tica que fertilizó las utopías sociales, donde el componente educativo tenía una función decisiva. ${ }^{8}$

Utopías y sueños los hubo desde distintas tendencias e iniciativas. Una de ellas fue la que se dirigió a atender a las poblaciones marginales y rurales, como fue el caso de Johann Heinrich Pestalozzi (Suiza, 17461827), de filiación masónica y próximo a los círculos culturales progresistas de Lombardía, quien planteó iniciativas novedosas para educar al pueblo. Seguidor de algunos de los planteamientos de Rousseau (17121778), como lo era la confianza en la bondad natural del niño y el compromiso del maestro para protegerlo dejando que afloraran sus propias virtudes, y reconociendo, por sobre el aprendizaje de memoria de reglas gramaticales y el cuestionado verbalismo, las posibilidades que ofrecía la intuición, le fue dando forma a sus ideas pedagógicas vertidas en distintos textos. ${ }^{9}$ De Pestalozzi, conocedor en profundidad de los ambientes rurales e imbuido de la sensibilidad hacia la naturaleza que el romanticismo alemán exaltara, procederá una de las imágenes más conocidas del educador como jardinero, que conoce los ritmos de la naturaleza y el comportamiento del educando:

[...] riega la tierra seca para que la raíz no muera, canaliza las aguas estancadas para que no se corrompan, pone atención en que ni raíces, ni tronco, ni las ramas reciban daños que obstaculicen el desarrollo natural y crecimiento armonioso de las partes. De este modo sólo el árbol crece fuerte y frondoso. ${ }^{10}$

Hay un dato en el contexto de la accidentada trayectoria de Pestalozzi que puede resultarnos revelador de las influencias-tradiciones que la región morava tuvo sobre él en relación con el parangón que llegó a establecer entre la acción educadora y el cultivo de la tierra (señalo ahora y retomo más adelante): de la simpatía que sentía por la aristocracia ilustrada y la confianza en que burgueses se comprometerían con la educación del pueblo, fue reorientándose hacia el pensamiento ma-

\footnotetext{
${ }^{8}$ Antonio Santoni Rugiu, Milenios de sociedad educadora, vol. 2. De la consolidación de la educación moderna a la educación de nuestros días (México: Educación, voces y vuelos, 2004), 171 y ss.

9 Johann Heinrich Pestalozzi, Cómo Gertrudis enseña a sus hijos; Cartas sobre la educación de los niños; Libros de educación elemental (México: Porrúa, 1976), y El canto del cisne (México: Porrúa, 1982).

${ }^{10}$ Pestalozzi, Cartas sobre la educación de los niños, 113.
} 
sónico en estrecho contacto con Nicolaus Ludwig von Zinzendorf, reformador religioso y obispo de los Hermanos Moravos (Berlín, 1737), quienes se inspiraban en el mismo Comenio, cuya visión social era más moderna y menos localista. ${ }^{11}$

Un paso definitivo, más allá de las aportaciones de Pestalozzi en el terreno de la pedagogía, lo dio Friedrich Fröbel (Turingia, 1782-Mariental, 1852) al darle forma definitiva al Jardín de Niños, como una opción moderna frente a las salas de asilo o de custodia que iban surgiendo para 'depositar' a los niños pequeños cuyos padres trabajaban en la industria. Fröbel, ${ }^{12}$ al igual que Pestalozzi, tenía en su haber un fuerte contacto con los guardabosques y los leñadores de Turingia, así como la experiencia de cuidar el huerto familiar, lo cual le dejó dos pistas educativas que desarrollaría de por vida: la riqueza del contacto con la naturaleza y la conciencia del significado del trabajo. En medio de sus avatares, por lo demás, estuvo en contacto por diversas vías con seguidores de Pestalozzi e incluso estuvo con él durante cuarenta días (Yverdon, 1802). Influido por círculos masónicos, por el fervor nacionalista de poetas y literatos, como Fichte, y en contacto con filósofos y escritores románticos de la talla de Richter, Schelling y Schiller, y de pensadores tales como Comenio, Locke, Rousseau y Owen, quedará siempre del lado de los progresistas.

En una singular síntesis que renovaría a fondo las prácticas del momento, reconoce el valor del juego, que ya proclamaba Schiller, ${ }^{13}$ con la novedad de combinarlo con el espíritu del trabajo en la formación de los niños pequeños (el juego como trabajo, el trabajo como juego); asume la importancia de la mujer como educadora integrándola las nuevas instituciones como parte del contacto con la vida familiar, con la comunidad, así como el recurso de los 'dones', el pedacito de tierra de cultivo, las actividades relacionadas con diversos oficios y, por supuesto, cantar, jugar y contar cuentos.

\footnotetext{
11 Santoni Rugiu, Milenios de sociedad educadora, 192.

12 Santoni Rugiu, Milenios de sociedad educadora, 243 y ss.

13 Schiller escribió un texto en el que exaltaba las cualidades de los niños como seres naturales que inspiraban afecto y emoción, fuente de inspiración para volver a ser lo que alguna vez fuimos. Véase Hugh Honour, El Romanticismo (Madrid: Alianza Forma, 1996): 322).
} 
Finalmente, no exento de varios ensayos, de dificultades de todo tipo y posteriores persecuciones ideológicas, Fröbel fundó el Instituto de Actividades para Párvulos (Blankenburg, Alemania,1837), una institución en contacto con la naturaleza y con un programa de actividades libres y novedosas (cantar, bailar, jugar, cultivar la tierra), que pocos años después llamaría Kindergarten o Jardín de Infancia (1840), con el acierto, además, de integrar a las mujeres formándolas como maestras jardineras. Al respecto, estuvieron presentes las aportaciones comenianas referidas a la Escuela materna en las que destacó el papel de la mujer como educadora, ${ }^{14}$ que habría de educar no sólo a los propios hijos sino a los niños de la comunidad, remitiendo al pequeño mundo de las familias tradicionales campesinas, en crisis por el desplazamiento hacia las grandes ciudades y la emergencia del «trabajo de fábrica». Por lo demás, reposicionaba a las mujeres en una nueva ocupación que las dignificaba.

El proyecto tuvo gran aceptación y se difundió rápidamente en la región germana y en otros países occidentales alrededor de la segunda mitad del siglo XIX y principios del siglo xx, momentos en que se incrementó la necesidad de las madres trabajadoras de dejar a los hijos en un lugar amable en vez de las lóbregas estancias infantiles.

El contacto con la naturaleza, que había marcado a Fröbel desde años tempranos y la influencia pestalozziana, lo llevaron a defender la metáfora del educador como un jardinero que transforma un terreno árido en un jardín florido. La nueva institución educativa se llamaba jardín no sólo porque debería vivir lo más posible en la verde naturaleza, sino porque parangonaba al niño con una planta que debe ser atendida y cuidada para crecer en el mejor de los mundos posibles.

Finalmente, Fröbel, se conocería como el «pedagogo del romanticismo», y razones no sobraron para ello.

Ahora bien, en México, como en otros países occidentales, puede decirse que la situación sustancialmente no difirió: hacia las últimas décadas del siglo XIX, en el contexto de la modernización del país y la estruc-

\footnotetext{
${ }^{14}$ Si bien el juego había sido preconizado por Schiller como una actividad humana superior, Fröbel es quien se atrevió a proponerlo como uno de los recursos educativos idóneos, y no sólo como entretenimiento o premio para los niños. (Santoni Rugiu, Milenios de sociedad educadora, 244).
} 
turación del sistema escolar, se introdujeron propuestas renovadoras procedentes de Fröbel, como una alternativa avanzada frente a lo que se conocía como educación de párvulos, esto es, niños menores de seis años. Las iniciativas de renovar estas escuelas, orientadas hacia lo que se estaba constituyendo como educación pre-escolar, proceden de 1881; 1883 resultará ser un año decisivo en relación con la institucionalización del Jardín de Niño, pues en Xalapa se funda la primera escuela de este tipo por iniciativa de Enrique Laubscher (Baviera, 1837-México, 1890), lo cual no es una casualidad: en Alemania había sido discípulo de Fröbel.

Los años que siguieron fueron decisivos: en 1902 se enviaron dos maestras mexicanas (Rosaura Zapata y Elena Zapata) a Estados Unidos (Nueva York, Boston y San Francisco) para observar los principios fröbelianos en las estancias de párvulos, de donde derivó tanto su aplicación en las estancias de párvulos en México como la promoción de la formación de maestras en este sentido, lo cual motivaría que las autoridades enviaran a Bertha von Glümer (Acapulco, 1877-México, 1963) a la Normal Fröbel de Nueva York para estudiar lo referente a la formación de las educadoras. ${ }^{15}$ La designación de escuelas de párvulos en México se mantuvo hasta 1907, año en que se sustituyó por la de Kindergarten que un poco más adelante se tradujo como Jardín de Niños o Jardín de la Infancia. ${ }^{16}$

Hasta aquí, todo bien. Es comprensible que el lenguaje metafórico, que remite a la naturaleza como paradigma de la institución educativa avocada al cuidado de los niños pequeños, se aplicara a los centros in-

\footnotetext{
${ }^{15}$ En el caso de México, también se cuentan entre las pioneras de este movimiento, a Estefanía Castañeda, Rosaura Zapata, Laura Méndez de Cuenca, entre otras.

${ }_{16}$ Anne Staples, «Panorama educativo al comienzo de la vida independiente», en Ensayos sobre historia de la educación en México, ed. Josefina Vázquez y otros (México: El Colegio de México, 1981), 101-144; Celia Reyes Anaya, La Educación Preescolar en México (México: Fontanella, 1983); Secretaría de Educación Pública, Reseña Histórica de los Jardines de Niños en México 1917-1942 (México: Talleres Gráficos de la Nación, 1985); Mílada Bazant, Historia de la educación durante el porfiriato (México: El Colegio de México, Centro de Estudios Históricos, 2006); Luz Elena Galván y Alejandra Zúñiga, «De las escuelas de párvulos al preescolar. Una historia por contar», en Diccionario de historia de la educación, ed. Luz Elena Galván (México: CONACyT, UNAM-DGSCA, CIESAS, 2009, versión digital). De años recientes puede mencionarse la indagación de Élida Lucila Campos Alba, De las Escuelas de Párvulos a los Jardines de Niños. Construcción de la cultura escolar en educación preescolar del Estado de México, 1881-1926 (México: El Colegio Mexiquense, 2013), quien se aproxima a este universo con las herramientas que le aporta la nueva historiografía de la educación y aporta claves importantes en su comprensión.
} 
fantiles que surgían desde los parámetros de la pedagogía moderna. Atrás de las imágenes del cultivo del jardín, de la labor del jardinero, del pulso de los tiempos y del terreno para sembrar, se filtraba el romanticismo alemán y la perspectiva de un proyecto ilustrado, pero no podemos perder de vista algunos de los legados comenianos gestados en otra época y transmitidos a través de las relaciones inéditas entre pensadores y reformadores de la región germano-morava, entre reformadores de distintos credos. Todo ello nos lleva a hurgar más atrás, en el siglo anterior, el de Juan Amós Comenio (Uherský Brod, 1592-Amsterdam, 1670), en el umbral de la modernidad.

\section{METÁFORAS VISUALES DE COMENIO}

El pensador moravo participó de la cultura visual de su época y logró con sus aplicaciones a la enseñanza del latín en lengua vernácula, una de las aportaciones que reconocerían los siglos posteriores a través de su obra cimera Orbis sensualium pictus (Amsterdam, 1658), cuyo acierto fue integrar una imagen con un breve texto en latín que la describía, agregando con las correspondientes columnas en lenguas vernáculas. ${ }^{17}$ En el conjunto de los ciento cincuenta capítulos que la integran nos muestra cuadros realistas sobre las creencias, saberes, ocupaciones e instituciones sociales de su momento. Sin embargo, el pensador moravo no fue ajeno al lenguaje simbólico de la época expresado a través de emblemas; en algunas ocasiones, por demás significativas, echó mano de él.

Interesa no perder de vista que Comenio experimentó de lleno la cultura del barroco que conjugó imagen y palabra; en ella tuvieron un lugar central emblemas, empresas y metáforas, cada una desde su particularidad. La metáfora, sin embargo, de acuerdo con algunos tratadistas de los siglos XVI y XVII, era la matriz de los emblemas. Con el emblema, estamos frente a «una figura simbólica acompañada de un breve lema explicativo y de un epigrama, destinado a transmitir, de manera más o menos intuitiva, una enseñanza moral, religiosa o política», ${ }^{18}$ y es en este sentido en el que me remito a ese concepto.

\footnotetext{
${ }^{17}$ En México hicimos la versión trilingüe latín, español e inglés: Juan Amós Comenio, El mundo en imágenes (México: CONACyT-Miguel Ángel Porrúa, 1993).

18 José M. González García, «De la metáfora al concepto: emblemas políticos en el barroco», Res publica 3 (1999): 83-106, cita en p. 84.
} 
Hay un emblema que Comenio emplea recurrentemente desde mediados del siglo XvII. La solución menos elaborada, pudiéramos decir (figura 1), la aplica a la portada de su Vestibuli et Janua Lingvarum Lucidarium (1653), así como al primer volumen de su Opera Didactica Omnia (Amsterdam, 1657); la solución más elaborada (figura 2), la emplea en la portada del Orbis Sensualium Pictus (Amsterdam, 1658, editio princeps), así como en los volúmenes II, III y IV de la mencionada Opera Didactica Omnia.

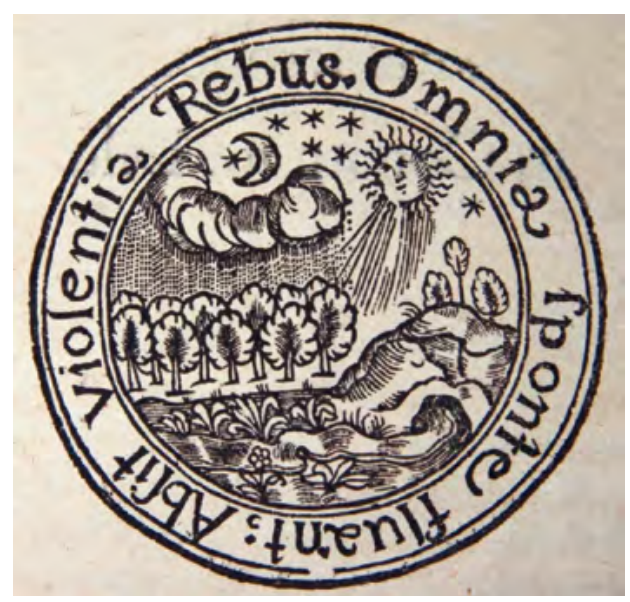

Figura 1. Versión preliminar del emblema comeniano Fotografía: Maria Římovská

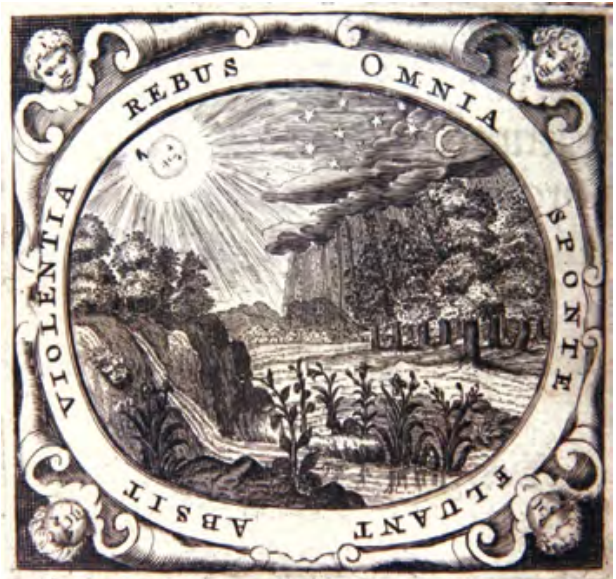

Figura 2. Versión más frecuente del emblema comeniano Fotografía: Maria Římovská

Se sabe, de acuerdo con indagaciones hechas por Klaus Schaller, que no fue dibujado por Comenio sino tomado de la literatura emblemática de su tiempo. ${ }^{19}$ Se le sitúa en la literatura checa de los siglos Xv y XVI. ${ }^{20}$

Pero, ¿cuál pudo ser el sentido de introducirlo en las primeras páginas de la edición del conjunto de sus escritos pedagógicos? Podemos ubicar dos planos de interpretación:

\footnotetext{
${ }^{19}$ Cfr. Klaus Schaller, Comenius 1992. Gesammelte Beiträge zum Jubiläumsjahr (Bochum: Academia Verlag, Schriften zur Comeniusforschung, Band 22, 1992), 140-141.

${ }^{20}$ Información recabada en el Museo Comeniano de Juan Amós Comenio de Uherský Brod, con la colaboración de Dana Večeřová.
} 


\section{El cultivo de la Naturaleza como modelo formativo}

Comenio tiene en su haber una amplia experiencia en la conducción de grupos, sea como último pastor de la Unitas Fratrum, sea como docente en las diversas escuelas de la Hermandad. La didáctica es una de sus preocupaciones tempranas; de hecho en los países de lengua española ha sido conocido fundamentalmente por su Didáctica Magna. ${ }^{21}$ En el umbral de la modernidad hace de sus aportaciones a este campo, motivo de reflexión, de argumentación; intercambia puntos de vista con sus interlocutores, se informa sobre los avances en otras regiones, siempre ocupado en dar sustento a la tarea de cómo enseñar todo a todos totalmente (Omnes, omnia, omnino).

Sólo que la racionalidad con que Comenio reviste su discurso didáctico en particular, y educativo en general, nos remite a la expresión analógica de su pensamiento: en la Didáctica Magna, obra en la que sistematiza su experiencia como maestro, Comenio plantea constantes puntos de encuentro y de convergencia entre su visión sobre la formación humana, como campo de problemas, y el cultivo de la Naturaleza, que aporta el modelo educativo, lo cual le sirve para avanzar explicaciones y fundamentar lo que propone.

Formado en las tradiciones humanísticas se apropia de algunas nociones referidas a la condición artística de la Naturaleza, que manifiesta un orden propio e interviene en los procesos con la cualidad de su Arte:

Si aquello que recibe apoyo de la tierra a través de las raíces vive y prospera gracias a una actividad artística de la Naturaleza, seguro que la tierra misma es sostenida, con idéntica fuerza, por el arte de la Naturaleza. ${ }^{22}$

Asiduo lector de Plutarco, recuperado hacia la última parte del siglo xv, hace suyas muchas de las reflexiones expuestas en De liberis educandis, que atañen a las posibilidades de formar a los jóvenes, que ya habían prescrito, con otros fines y en otro contexto, los antiguos sofistas. El sustento de toda tarea dirigida al desarrollo del comportamiento

\footnotetext{
${ }^{21}$ Se publica en 1637. Es la traducción al latín de una versión ampliada de la Didáctica checa, escrita y publicada entre 1631 y 1632.

${ }^{22}$ Marco Tulio Cicerón, Sobre la naturaleza de los dioses (Madrid: Gredos, 1999), Libro II, 83.
} 
virtuoso, decíamos, lo aporta la Naturaleza, y el arte de cultivarla, la solución para mejorarla, enriquecerla, perfeccionarla por medio del razonamiento y la ejercitación:

De la misma forma que en la agricultura es necesario que, primeramente, la tierra sea buena; en segundo lugar, que el que planta sea hábil; en tercer lugar, que las semillas sean excelentes, en la misma forma la naturaleza se asemeja a la tierra; el educador, al agricultor; los consejos y preceptos de la palabra, a la semilla. ${ }^{23}$

Comenio recoge, asimismo, las antiguas tradiciones bíblicas, particularmente las del Nuevo Testamento, en las que el cultivo del campo se compara con el cultivo de la vida humana, su desarrollo interior; de tal modo, preparar la tierra, sembrar y cosechar los frutos se plantean como expectativas en relación con la vida futura. Sobre todo, la parábola de la siembra constituye una de sus imágenes favoritas, plena de sentido para la acción educativa que emprende, que, por lo demás, ofrece las posibilidades de salvación... Aquí podríamos subrayar que se trata de una preocupación que recorre los tiempos recreando sus sentidos (cito al azar a pensadores tan distantes como lo pueden ser san Isidro y Vasconcelos). ${ }^{24}$

Comenio, por su parte, no deja pasar oportunidad para referirse al cultivo de la naturaleza como modelo de enseñanza cuyos principios hay que inferir, a través de una cuidadosa observación de su comportamiento. Así, en el «Prefacio» de la Didáctica Magna, explicita a los lectores cuáles son los «fundamentos de tan novísimo arte» (sic):

[...] toda nuestra demostración será a priori, esto es, se basa en la mismísima naturaleza inmutable de las cosas, de donde como de fuente viva brotan riachuelos que, al unirlos de nuevo al caudal único, se establece un cierto arte universal, base de las escuelas universales. ${ }^{25}$

\footnotetext{
${ }^{23}$ Plutarco Sobre la educación de los niños (México: Facultad de Filosofía y Letras, UNAM, 1986), 25.

${ }^{24}$ En las culturas arcaicas, pero también de manera común en todos los pueblos, diversos aspectos que atañen a la vida del hombre se explican tomando referentes de la vida de las plantas.

25 Juan Amós Comenio, «A los lectores, Salud» [Prefacio inédito a la Didáctica Magna], en María Esther Aguirre Lora, Calidoscopios comenianos, II. Acercamientos a una hermenéutica de la cultura (México: Centro de Estudios Sobre la Universidad-Universidad Nacional Autónoma de México, Plaza y Valdés, 2001), 243-247.
} 
Más adelante se pregunta, rebatiendo la improvisación de los docentes: «¿Quién no sabe que hace falta cierto arte y pericia para sembrar y plantar?», ${ }^{26}$ y hace hincapié: «La idea universal del arte de aprender y de enseñar todas las cosas, no debemos ni podemos tomarla de otra parte que no sea de la enseñanza de la Naturaleza». ${ }^{27}$

Baste recorrer, particularmente, los subtítulos de los capítulos XVI, XVII y XVIII de la Didáctica Magna para apreciar el despliegue de toda una preceptiva y una argumentación basadas en este modelo: «La Naturaleza aprovecha el tiempo favorable» (p. 62), «La Naturaleza prepara la materia antes de empezar a darle forma» (p. 63), «La Naturaleza toma para sus operaciones a los sujetos aptos o también para hacerlos aptos los prepara adecuadamente» (p. 64), «La Naturaleza no se confunde en sus obras, procede claramente en cada una de ellas» (p. 65), «La Naturaleza empieza todas sus operaciones por lo más interno» (p. 66), «La Naturaleza parte en la formación de todas sus cosas de lo más general y termina por lo más particular» (p. 67), «La Naturaleza no da saltos sino que procede gradualmente» (p. 69), «La Naturaleza una vez que comienza no se detiene hasta terminar» (p. 70), «La Naturaleza evita diligentemente lo que le es contrario y nocivo» (p. 71) «La Naturaleza empieza siempre por despejar» (p. 72), «La Naturaleza predispone la materia para hacerle apetecer la forma» (p. 73), "La Naturaleza saca todo de sus principios, pequeños en tamaño, poderosos en energía» (p. 75), «La Naturaleza procede de lo más fácil a lo más difícil»(p. 76), «La Naturaleza no se recarga con exceso, se conforma con poco» (p. 77), «La Naturaleza no se precipita; procede, por el contrario, con lentitud» (p. 78), «La Naturaleza no produce sino lo que puede salir por sí una vez maduro interiormente» (p. 79), «La Naturaleza no produce sino lo que tiene un uso claro e inmediato» (p. 80), «La Naturaleza ejecuta todas las cosas con uniformidad» (p. 81), «La Naturaleza no emprende nada inútilmente» (p. 83), «La Naturaleza no omite nada de lo que estima provechoso para el cuerpo que forma» (p. 83), «La Naturaleza no hace cosa alguna sin fundamento o raíz» (p. 84), «La Naturaleza echa raíces profundas» (p. 84), «La Naturaleza produce todo por sus propias raíces, no de ningún otro origen» (p. 85), «La Naturaleza al

\footnotetext{
${ }^{26}$ Juan Amós Comenio, Didáctica Magna (México: Porrúa, 1988, 3. impresión), 61.

${ }_{27}$ Comenio, Didáctica Magna, 53.
} 
disponer algo para muchos usos, lo diferencia» (p. 87), «La Naturaleza se halla en progreso continuo, jamás se detiene, nunca emprende cosas nuevas dejando a un lado las anteriores, sino que prosigue lo que empezó, lo aumenta y le da fin» (p. 88), «La Naturaleza enlaza todas las cosas con vínculos perpetuos» (p. 88), «La Naturaleza guarda proporción entre la raíz y las ramas, tanto respecto de la cantidad como de la calidad» (p. 90), «La Naturaleza vive y se robustece con movimiento frecuente» (p. 90). ${ }^{28}$

Y alrededor de ello se tejen imágenes donde abundan las referencias a la preparación de la tierra, a la observancia del tiempo oportuno para la siembra, la elección de las semillas, al cuidado de cada una de las plantas, al crecimiento paulatino de los árboles, al equilibrio en el desarrollo de cada una de las partes de las plantas, al sentido de utilidad en cada una de las tareas que realiza el labrador, a la merecida cosecha... De estas imágenes se desencadenan principios y reflexiones que sustentan el Arte de intervenir en la naturaleza de los hombres, su didáctica, que propone como solución a los males sociales.

Cabe destacar, no obstante, que en este «arte» también se muestran, persistentes tradiciones alquímicas de las cuales Comenio participa, que plantean la gran transformación de hombres, sociedades y saberes requiriendo la perfección espiritual del maestro. El maestro comeniano, conocedor de los tiempos y ritmos de la naturaleza, deviene un Ministro Naturae cuya propuesta es hacer de todas las escuelas, hoy lugares de trabajo, lugares de juego (ludus):

Esto ocurrirá observando los momentos oportunos según las edades, de modo que no se haga nada (ni se comience a hacer) fuera del tiempo en que la naturaleza comienza a hacer sus propios partos; aunque no pueda hacerse nada más que ayudar a la Naturaleza en su parto [...]. Importa comenzar pronto, pero no tan pronto que se corrompa la naturaleza en vez de ayudarla. Ninguna madre puede parir antes de tiempo ni se le puede obligar a que lo haga, tampoco ningún entendimiento puede pa-

\footnotetext{
28 Comenio. Didáctica Magna, 62-90.
} 
rir antes de su momento o parirá un aborto. Cada cosa tiene su tiempo. ${ }^{29}$

Finalmente, volviendo al emblema, la imagen de un bosque donde fluye libremente un riachuelo, enmarcada en el lema: «Omnia sponte fluant- Absit violentia rebus», señala la dirección de la intervención pedagógica que se desea: afable, afectuosa, no violenta.

Aquí también recoge las enseñanzas de Plutarco: «[...] es necesario conducir a la juventud hacia las formas bellas de vivir, con recomendaciones y discursos, no ipor Zeus!, con golpes ni malos tratos». ${ }^{30} \mathrm{Y}$ también las de Campanella respecto al amor que debe prevalecer en el ámbito de los que enseñan. ${ }^{31}$

Pero los niveles de significación del emblema no se detienen en el plano del modelo pedagógico de referencia y del necesario sustento de las tareas docentes, como a continuación veremos.

\section{El cultivo de la Naturaleza como restauración humana}

Resulta interesante caer en la cuenta de que la Didáctica Magna o Tratado universal del Arte de Enseñar, que hace del cultivo de la naturaleza su paradigma, tiene un carácter milenarista, como Comenio explícitamente plantea a los lectores desde su inicio:

El contenido de estas páginas es de extrema seriedad, y no sólo debe ser ardientemente deseado por todos, sino que requiere de la ponderación de todos y la conjugación de fuerzas para ir siendo implementado: se trata nada menos que de la salvación del género humano. ${ }^{32}$

\footnotetext{
29 Juan Amós Comenius, Pampedia (Madrid: Universidad Nacional de Educación a Distancia, 1992), 158-159.

${ }^{30}$ Plutarco, Sobre la educación de los niños, 45.

${ }_{31}$ Tommaso Campanella, «La ciudad del sol», en Utopías del Renacimiento, ed. Eugenio Imaz (México: Fondo de Cultura Económica, 1956), 143-221, cita en p. 156.

32 Plutarco, Sobre la educación de los niños, 45 [El subrayado es mío].
} 
Más adelante, exhorta:

Con razón, pues, pido a mis lectores; más aún conjuro por la salud del género humano a quienes lean este escrito: primero, que no juzguen de temerario a quien no sólo intenta tan gran tarea, sino que la promete: valga la pena que esto conlleva una finalidad salvifica. ${ }^{33}$

Por otra parte, el comeniólogo alemán, Klaus Schaller, aporta claves importantes para comprender el mensaje de este emblema, referido a una de las obras en las que Comenio vierte su experiencia como maestro: Se trata de una reveladora dedicatoria de la Didáctica checa (16311632), escrita ya en el exilio, que años después reformularía y traduciría al latín como Didactica Magna (1637), con el propósito de que circulara en ámbitos más amplios que los de su región checa.

Según Schaller, hacia 1841 los predicadores Jan Evangelista Purkyně y Josef Kacer, descubrieron en Lezno (Polonia) el manuscrito de esa versión preliminar de la Didáctica, para la que el Comenio proponía como subtítulo:

Paradisus renascentis ecclesiae, que se lleve a efecto sobre la fundación de la nueva Iglesia, esto es: practicar un nuevo seguro y noble Arte, que permita a la juventud cristiana una verdadera devoción, con una moral elevada, en el arte de la palabra y en todo conocimiento; para que ella, actuando como sobre los arbolitos en el paraíso de Dios, sabiamente ennoblezca, riegue, vea crecer, recorte y recolecte, de modo que crecen bien, reverdezcan, orezcan y den frutos de buen sabor para plenitud de su Dios y de la Iglesia. ${ }^{34}$

\section{El propio Comenio dudó si mejor subtitularla}

Paradisus Bohemiae, esto es, la nueva, comprensible, pública y vital fundación de escuelas, bajo cuya influencia se desea que la Iglesia y el cuerpo del estado bohemio, después de su triste y

\footnotetext{
${ }^{33}$ Comenio, «Prefacio a la Didáctica magna», 244. Lo llamé así porque el texto de Comenio se llama «A los lectores, Salud».

${ }^{34}$ Schaller, Comenius 1992, 138.
} 
terrible corrupción, crezcan vigorosamente como en el Jardín del Edén. ${ }^{35}$

Finalmente, años después, el subtítulo de la Didactica Magna, desplazaría a los anteriores por el siguiente:

Tratado general de la enseñanza para que todos puedan aprender todo por medio de seguros y selectos procedimientos y para que se funden tales escuelas en las comunidades, las ciudades y los pueblos de todo reino cristiano, en las que toda la juventud de ambos sexos, sin excepción, se instruya, se forme en las buenas costumbres, plena de devoción, de modo que sea provechoso dirigirla tanto para la vida del presente como para la del futuro. ${ }^{36}$

Por lo demás, cabe señalar que la intención de hacer de las escuelas lugares en los que se restaure el paraíso original, es un tema recurrente en la obra de Comenio.

Otro dato importante es que el empleo de este emblema se da hacia mediados del siglo XVII, después de la breve estancia de Comenio con los milenaristas ingleses (1642), años en los que la obsesión por la Reforma universal se apodera absolutamente de él y le queda claro que su compromiso con el mejoramiento de las escuelas tiene sentido solamente en relación con el programa más amplio de Reforma cristiana.

En este contexto es posible apreciar en el emblema otros significados. Ciertamente el emblema comeniano integra imágenes de la naturaleza - bosques, montes, ríos, sol, nubes, lluvia-, pero siempre de manera armónica, apacible, que nos remiten al sentido de una naturaleza encauzada, cultivada, fértil, vigorosa pero plácida, que subraya apropiadamente el lema que enmarca las imágenes: Omnia sponte uant-Absit violentia rebus y, en este sentido, más próxima al jardín, e incluso al Jardín primordial. La Biblia, desde el Génesis, plantea referencias constantes al edén: «Dios tomó al hombre y lo colocó en el jardín del Edén, para que lo cultivara y lo cuidara». ${ }^{37}$

\footnotetext{
${ }^{35}$ Schaller, Comenius 1992, 139.

${ }^{36}$ Schaller, Comenius 1992, 139.

37 Génesis, 2, 15.
} 
La obra comeniana, como decíamos, es rica en constantes referencias a la naturaleza cultivada, a jardines, a edenes, a paraísos primordiales y a la posibilidad de su recuperación terrenal. Lo que él llama Pampedia, que es el Libro IV de la Consulta Universal, se refiere a lo que hoy sería una teoría general de la educación —no sólo de la enseñanza y del aprendizaje-; no consiste en otra cosa que en:

[...] el arte de implantar la sabiduría en las mentes, en las lenguas, en los corazones y en las manos de todos los hombres. Con esta intención en el frontispicio de esta obra colocamos un símbolo extraído del arte del injerto: los injertadores escogen en el árbol de la pansofía yemas y las injertan en nuevos árboles, ávidos de llenar con pequeños árboles de naturaleza semejante todo el jardín de Dios, a saber, el género humano. ${ }^{38}$

El jardín es, pues, el paraíso de los primeros tiempos, el jardín cultivado e idílico que todos los cristianos añoran y desean restaurar; la Consulta universal para la enmienda de los asuntos humanos, y la Pampedia, o educación de todos en todo, aportan las herramientas para ello. Y qué mejor oportunidad que intervenir en la crianza de niños y jovencitos que harán las veces de retoños sanos, fuertes y cultivados que podrán reforestar y restaurar el jardín primordial...

No por casualidad nuestro pensador moravo propuso que la enseñanza de los niños pequeños se graduara en relación con escuelas (grupos de edades) que remiten, siempre, a las imágenes de cultivo, de siembra: plantarium (vivero), seminarium (semillero), violarium (campo de violetas), rosarium (rosaleda), viridarium (vergel), paradisus (jardín).

La analogía entre el cultivo del jardín y la educación de los pequeños plantea múltiples inferencias respecto a la tarea del educador si tenemos presente que el jardín es aquella parte de la naturaleza protegida, cultivada, motivo de cuidados especiales que propician el crecimiento privilegiado de las plantas, también excepcionales, que en él se alberguen. Ahí, cada una de las plantas habrá de manifestar la riqueza y los matices del flujo de la vida; cada una será motivo de un tratamiento especial durante su desarrollo. En este espacio privilegiado es posible ob-

\footnotetext{
${ }^{38}$ Comenius, Pampedia, 45.
} 
servar y experimentar un Arte para el logro de determinados efectos, ya que se trata de un espacio controlado, acotado; las plantas, por su parte, en su maduración a partir de la semilla, evocan, a la vez, un proceso de crecimiento que se gesta desde su interior, que impulsa lo que la semilla contiene en germen.

El lema por sí mismo rechaza la violencia de los tiempos de crisis que viviera Comenio. Es contrario a todo tipo de interferencias y obstáculos para el advenimiento de la Edad de Oro del Cristianismo; ${ }^{39}$ a la vez, se proyectan las condiciones deseables de la educación.

\section{A MODO DE CIERRE}

El concepto de naturaleza, y las metáforas que en él se pudieran alojar, no es estático; incorpora las tradiciones de cada época, las creencias, los imaginarios colectivos, el lenguaje, la memoria de todos. En una forzada modernidad es frecuente que despojemos a Juan Amós Comenio de las marcas propias de su época, de las culturas en la que participó y desde las que construyó sus propias aportaciones, pero no podemos omitir que fue un reformador religioso perteneciente a la pequeña comunidad de los Hermanos Moravos (Unitas Fratrum), en estrecha relación con calvinistas y luteranos, quienes estaban comprometidos con la restauración del género humano, con el retorno a los orígenes del Paraíso, consigna en la que se encuentran sedimentadas tradiciones y creencias de su época, de su región.

Y si Comenio recurrió a la metáfora para reflexionar sobre la educación, para avanzar en su problematización y desde ahí sustentar su intervención, no podemos perder de vista que se trataría de las metáforas posibles para los reformadores religiosos de la región germano-morava en la medida que su proyecto de fondo, en el que coincidían las Iglesias Reformadas en medio de sus diferencias, era restaurar la pureza de los primeros tiempos del cristianismo. Las convicciones milenaristas y la esperanza en el advenimiento de una era en la que dominara el paraíso recuperado, harían de la educación uno de los recursos idóneos para la restauración del género humano y la realización del paraíso prometido.

\footnotetext{
${ }^{39}$ Giovanni Filoramo (ed.), Cristianesimo (Bari: Laterza, 2000).
} 
La metáfora del Jardín de Niños revistió distintos significados en los contextos del romanticismo alemán, donde la institución avocada a los niños en edad pre-escolar se planteaba como un proyecto de la modernidad vinculado con la escolarización. Al respecto, es importante no perder de vista las condiciones históricas, económicas, sociales y culturales que harían posible el surgimiento de estos lugares: el despliegue del movimiento ilustrado con sus afanes modernizadores, las oleadas de las revoluciones industriales, las nuevas formas de organización social, las exigencias que planteaban las formas de trabajo femenil en el desplazamiento a los núcleos urbanos, el cambio de valencia de las tradiciones gestadas en torno al asistencialismo infantil, la emergencia de nuevos sujetos de la educación a tono con las formas de clasificación que se ensayaban sobre la población.

Lo interesante, a fin de cuentas, es visibilizar las historias sedimentadas en una de nuestras instituciones escolares más sólidamente establecidas, del todo naturalizada en nuestra vida cotidiana.

\section{Nota sobre la autora}

María Esther Aguirre Lora es Profesora en el Posgrado en Pedagogía y en el Posgrado en Educación Musical e investigadora titular en el Instituto de Investigaciones sobre la Universidad y la Educación (UNAM). Cultiva campos de indagación, la historia social y cultural de la formación artística y la nueva historia de la educación. El Museo Pedagógico de Praga le otorgó la medalla Jan Amos Komenskeho como reconocimiento a sus trabajos referidos a este autor (1994). Es miembro de la Academia Mexicana de Ciencias; fue presidenta de la Sociedad Mexicana de Historia de la Educación; fue distinguida en la UNAM con el reconocimiento «Sor Juana Inés de la Cruz»; obtuvo el Premio Universidad Nacional 2011 en el área de Investigación en Humanidades. Pertenece al Sistema Nacional de Investigadores, nivel 3. Entre sus últimas publicaciones, se puede mencionar: Rememorar los derroteros. La impronta de la formación artística en la UNAM (2015); Narrar historias de la educación. Crisol y alquimia de un oficio (2015). Campo 9, Historia e historiografía de la educación en México. Hacia un balance 2002-2012 (2016); y Modernizar y reinventarse. Escenarios de la formación artística (ca. 1920-1970) (2017). 


\section{REFERENCIAS}

Aguirre Lora, Ma. Esther (coord.). Juan Amós Comenio: obra, andanzas, atmósferas (libro y cassette). México: Centro de Estudios Sobre la Universidad-Universidad Nacional Autónoma de México, 1993.

Aguirre Lora, Ma. Esther. Calidoscopios comenianos, II. Acercamientos a una hermenéutica de la cultura. México: Centro de Estudios Sobre la Universidad-Universidad Nacional Autónoma de México, Plaza y Valdés, 2001.

Alessio, Franco, Fabietti, Renato y Papi, Fulvio. Filosofie e società, 3 vols. Bologna: Zanichelli, 1989.

Amilburu, María G. «Las metáforas de la educación». En Antropología de la Educación, editado por Henri Bouché y otros, 187-206. Madrid: Síntesis, 2002.

Bazant, Mílada. Historia de la educación durante el porfiriato. México: El Colegio de México, Centro de Estudios Históricos, 2006.

Bruner, Jerome. La educación, puerta de la cultura. Madrid: Visor, 1997.

Campos Alba, Élida Lucila. De las Escuelas de Párvulos a los Jardines de Niños. Construcción de la cultura escolar en educación preescolar del Estado de México, 1881-1926. México: El Colegio Mexiquense, 2013.

Capková, Dagmar. "J.A. Comenius's "Orbis Pictus" in its Conception as a Textbook for the Universal Education of Children». Paedagogica Historica, International Journal of the History of Education 10 (1970): 5-27.

Debus, Allen G. El hombre y la naturaleza en el Renacimiento. México: Fondo de Cultura Económica (Breviarios, 384), 1985.

Eisner, Elliot W. «Instructional and Expresive Objectives: Their Formulation and Use in Curriculum». AERA Monograph Series in Curriculum Evaluation 3 (1969, reimpreso en 1985): 1-21.

Filoramo, Giovanni (editor). Cristianesimo. Bari: Laterza (Biblioteca Universale, Storia delle religión), 2000.

Galván, Luz Elena y Alejandra Zúñiga. «De las escuelas de párvulos al preescolar. Una historia por contar». En Diccionario de historia de la educación, editado por Luz Elena Galván. México: CONACyT, UNAM-DGSCA, CIESAS, versión digital, 2009.

Garin, Eugenio. La revolución cultural del Renacimiento. Barcelona: Crítica Grijalbo, 1984.

Garin, Eugenio. La educación en Europa 1400-1600. Barcelona: Crítica Grijalbo, 1987.

González García, José M. «De la metáfora al concepto: emblemas políticos en el barroco», Res publica 3 (1999): 83-106. 
Honour, Hugh. El Romanticismo. Madrid: Alianza Forma, 1996.

Molina Iturrondo, Ángeles. «Las educadoras y sus metáforas educativas: dos investigaciones en acción», Anales de Pedagogía 19 (2001): 201-220.

Ortony, Andrew. «Metaphor: Theoretical and empirical research», Psychological Bulletin 85, 5 (1978): 919-943.

Petrie, Hugh G. «Do you see what I see? The epistemology of interdisciplinary inquiry», Educational Researcher 5, no. 2 (1976): 9-15.

Reyes Anaya, Celia. La Educación Preescolar en México, México, Fontanella, 1983.

Rodríguez Diéguez, José Luis. "Las metáforas en la enseñanza», Enseñanza \& Teaching, Revista interuniversitaria de didáctica 6 (1988): 205-222.

Rossi, Paolo y Maurice Slawski. Science, culture and popular belief in Renaissance Europe. Manchester: Manchester University Press, 1991.

Santoni Rugiu, Antonio. Milenios de sociedad educadora, vol. 2 de la consolidación de la educación moderna a la educación de nuestros días. México: Educación, voces y vuelos, 2004.

Schaller, Klaus. Comenius 1992. Gesammelte Beiträge zum Jubiläumsjahr. Bochum, Verlag Schriften zur Comeniusforschung, Band 22, 1992.

Scheffler, Israel. The Language of Education. Illinois: Thomas, Springfield, 1960.

Secretaría de Educación Pública. Reseña Histórica de los Jardines de Niños en México 1917-1942. México: Talleres Gráficos de la Nación, 1985.

Staples, Anne. «Panorama educativo al comienzo de la vida independiente». En Ensayos sobre historia de la educación en México, editado por Josefina Vázquez y otros, 101-144. México, El Colegio de México, 1981.

Vázquez Recio, Rosa. «Las metáforas, una vía posible para comprender y explicar las organizaciones escolares y la dirección de centros», REICE-Revista Electrónica Iberoamericana sobre Calidad, Eficacia y Cambio en Educación 5, n. 3 (2007): 137-151. 